\title{
ILCEA
}

Revue de l'Institut des langues et cultures

d'Europe, Amérique, Afrique, Asie et Australie

46 | 2022

Refuges identitaires numériques

\section{Feminidad y masculinidad más inclusivas y respetuosas hacia el colectivo LGTBIQ*: ¿Cómo representan los y las influencers españoles sus identidades de género?}

Une féminité et une masculinité plus inclusives et respectueuses envers le collectif LGTBIQ* : comment les influenceurs espagnols représentent-ils leurs identités de genre?

Femininity and Masculinity more Inclusive and Respectful towards the LGTBIQ* Collective: How do Spanish Influencers Represent Their Gender Identities?

Maddalena Fedele, Ester Villacampa y Sue Aran-Ramspott

\section{OpenEdition} Journals

\section{Edición electrónica}

URL: https://journals.openedition.org/ilcea/13824

DOI: $10.4000 /$ ilcea.13824

ISSN: 2101-0609

Editor

UGA Éditions/Université Grenoble Alpes

Edición impresa

ISBN: 978-2-37747-331-1

ISSN: $1639-6073$

Referencia electrónica

Maddalena Fedele, Ester Villacampa y Sue Aran-Ramspott, «Feminidad y masculinidad más inclusivas y respetuosas hacia el colectivo LGTBIQ*: ¿Cómo representan los y las influencers españoles sus identidades de género?», ILCEA [En línea], 46 | 2022, Publicado el 02 marzo 2022, consultado el 11 marzo 2022. URL: http://journals.openedition.org/ilcea/13824 ; DOI: https://doi.org/10.4000/ilcea. 13824

Este documento fue generado automáticamente el 11 marzo 2022.

(C) ILCEA 


\section{Feminidad y masculinidad más inclusivas y respetuosas hacia el colectivo LGTBIQ*: ¿Cómo representan los y las influencers españoles sus identidades de género?}

Une féminité et une masculinité plus inclusives et respectueuses envers le collectif LGTBIQ* : comment les influenceurs espagnols représentent-ils leurs identités de genre?

Femininity and Masculinity more Inclusive and Respectful towards the LGTBIQ* Collective: How do Spanish Influencers Represent Their Gender Identities?

Maddalena Fedele, Ester Villacampa y Sue Aran-Ramspott

\section{Introducción}

1 La investigación académica en comunicación ha destacado a menudo el papel de los medios en el proceso de socialización de adolescentes y jóvenes, en la construcción de su identidad individual y colectiva, y en la adquisición de valores, modelos y estereotipos (e.g.: Arnett, 1995; boyd, 2014; Ito et al., 2010; Ter Bogt, Engels, Bogers \& Kloosterman, 2010), incluidos aquellos relacionados con las identidades de género. Además, tanto la investigación académica como los datos nacionales e internacionales disponibles (AIMC, 2020; Anderson \& Jiang, 2018; Eurostat, 2018; IAB Spain, 2018; Ofcom, 2019) destacan la centralidad de los medios, y sobre todo de los social media, en las vidas de las juventudes de hoy en día. 
2 Tanto los social media como sus protagonistas más destacados, los llamado influencers o micro-celebrities (Marwick, 2015; Senft, 2008), son, de hecho, parte integrante de una cultura juvenil mediatizada, que proporciona a adolescentes y jóvenes herramientas para la construcción de sus identidades individuales y colectivas, que estos colectivos interpretan e incorporan de manera activa (Aran-Ramspott, Fedele \& Tarragó, 2018; Fedele, Aran-Ramspott \& Suau, 2021). Es decir, tanto los social media como los influencers forman parte de lo que ha sido definido "vida mediática» (Deuze, 2011 y 2012; Mancovich, 2009) de sus audiencias, o, también, «nuevo ecosistema mediático» (Jenkins, Ito \& boyd, 2016; Press \& Williams, 2010; Scolari \& Fraticelli, 2017), que representa el terreno (virtual) propicio para la construcción de las identidades fluidas (Bauman, 2001) e híbridas (Maloney, Roberts \& Caruso, 2018) en la modernidad tardía (Beck, 1992; Giddens, 1995).

3 La literatura ya ha reconocido a los medios de comunicación tradicionales al menos cuatro tipos de funciones sociales en la vida de sus audiencias - de entretenimiento, de situación de consumo, narrativas y de socialización (Fedele, 2011). En el actual ecosistema mediático, además, precisamente los social media, como YouTube, Instagram, Facebook, Snapchat, TikTok o Twitter, se pueden entender como espacios privilegiados para la construcción y la (auto)representación de la identidad (boyd, 2014; Cover, 2012; Prades \& Carbonell, 2016; Thumim \& Enli, 2012), sobre todo a través de sus microcelebridades. Además, numerosas investigaciones señalan que las audiencias jóvenes pueden establecer relaciones parasociales con los influencers (Ferchaud, Grzeslo, Orme \& LaGroue, 2018; Rasmussen, 2018; Rihl \& Wegenerpp, 2017), quiénes pueden actuar como modelos de conducta (Westenberg, 2016) a través de mecanismos de identificación y admiración (Aran-Ramspott et al., 2018).

Por otro lado, hay que destacar que las actuales generaciones jóvenes, usuarias de social media, pertenecen a la llamada Generación Z (o Centennials), posterior a la Generación Y de los Millennials (Fernández-Cruz \& Fernández-Díaz, 2016; Howe \& Strauss, 2000; Ortega \& Vilanova, 2017; Schroer, 2008), a la que a menudo pertenecen los influencers protagonistas de dichos medios. Aunque la Generación Z, referida a personas nacidas entre 1995 y 2012, puede considerarse como la primera verdaderamente digital, ambas generaciones se consideran inclusivas e identificadas con los valores de la igualdad y la no-discriminación. Valores que encuentran precisamente en YouTube un medio adecuado para ser expresados, al ser esta plataforma mayormente poblada por jóvenes (Van-Dijck, 2007), y reconocida por las posibilidades de visibilidad y normalización que ofrece al colectivo LGTBIQ+ (Abidin \& Cover, 2018; Blanco-Ruiz \& Sáinz de Baranda, 2018; Lovelock, 2017; Pérez-Torres, Pastor \& Abarrou, 2018).

5 Por lo tanto es necesario preguntarse qué representaciones mediáticas están proporcionando los jóvenes influencers a sus seguidores, precisamente para detectar posibles modelos, estereotipos y valores ligados a las representaciones de género.

\section{Social media, influencers y representación de género}

6 Por el rol socializador que los influencers pueden tener, son abundantes los estudios sobre la penetración de la sensibilidad postfeminista en la cultura popular y sobre su pervivencia en las redes sociales (Banet-Weiser, 2011; Campos de Cerqueida, 2017; Dobson, 2012; Vaisman, 2016). Hay que destacar que la cuarta ola feminista (Cochrane, 2013; Munro, 2013) y la notoriedad del feminismo popular (Banet-Weiser, 2018) están 
influyendo en la construcción del imaginario digital entorno a la construcción de género, dando lugar a representaciones más diversas e inclusivas que invalidan parcialmente las tesis postfeministas (Caballero, Tortajada \& Willem, 2017; Keller \& Ryan, 2018). De igual manera, los usuarios masculinos de redes sociales presentan identidades híbridas y comportamientos ambivalentes en torno al género (Maloney et al., 2018; Morris \& Anderson, 2015).

7 Aunque estos estudios hayan detectado representaciones de género más diversas e inclusivas, otras también han destacado que sigue perviviendo un sesgo de género (prevalentemente binario) en la desigual representación y repercusión de los influencers, así como en el tipo de contenido producido (García-Jiménez, García \& López de Alaya, 2016; Mollyneaux, Gibson, O’Donnell \& Singer, 2008). Por ejemplo, algunas investigaciones han criticado la escasa representación femenina que existe en YouTube (Wotanis \& McMillan, 2014), mientras que los datos indican que de los 1,68 billones de usuarios en 2019 (Tankivska, 2021), el 56\% son hombres (Newberry, 2021). También en el caso de Instagram, red social en la que casi el $40 \%$ de usuarios tiene menos de 34 años, hay más usuarios hombres que mujeres en las franjas de edades 18-24 años y 25-34 años (Statista, 2021). Por otro lado, según Rihl y Wegenerpp (2017), no se han identificado diferencias notables entre las relaciones que establecen hombres y mujeres con las celebridades de YouTube.

8 En cambio, sí que se detecta un sesgo de género en la preferencia de plataformas: mientras las chicas adolescentes optan mayoritariamente por Instagram, los chicos se inclinan por YouTube (García-Jiménez et al., 2016). También se ha demostrado que las mujeres suben menos posts a los Vlogs de YouTube, aunque son más activas a la hora de interactuar con otros Vlogs, y presentan una mayor tendencia a tratar asuntos personales (Molyneaux et al., 2008). La desigualdad también se manifiesta en la división del consumo, puesto que los canales de juegos son los más populares entre los chicos y los de moda y belleza entre las chicas (Garmendia et al., 2018; Linares-Bahillo, AristeguiFradua \& Beloki-Marañon, 2019). También entre preadolescentes, se ha encontrado que las chicas tienden más a un uso de las redes sociales y a una relación con los influencers con funciones socializadoras, mientras que los chicos muestran un uso de los contenidos más relacionado con el entretenimiento y a una relación con los influencers más cercana a elementos de identificación (Aran-Ramspott et al., 2018; Fedele et al., 2021).

\section{Diseño metodológico}

9 Este artículo presenta la primera parte de los resultados de un estudio más amplio sobre la relación entre los jóvenes influencers españoles y sus audiencias Millennials y Centennials. El objetivo principal del presente artículo es identificar y analizar las representaciones mediáticas ofrecidas por diez jóvenes influencers españoles (Tabla 1), en relación a la construcción de las identidades de género (incluidas las categorías de género no binario). De este objetivo principal se desprenden los siguientes subobjetivos:

1. Analizar las características físicas, sociales y psicológicas que permiten identificar a los influencers de la muestra como «personajes», y relacionar estos rasgos con las representaciones de género; 
2. Averiguar posibles diferencias en función del género en el uso del lenguaje audiovisual y de los recursos visuales propios de las dos plataformas analizadas;

3. Identificar la autorepresentación de género presente en los contenidos mediáticos producidos por los influencers de la muestra.

Para abordar estos objetivos, el diseño metodológico del estudio ha incluido, respectivamente:

a. Un análisis socio-semiótico de los influencers entendidos como personajes (Fedele, 2014), que incluye el análisis de sus características físicas (como la constitución física, tipo de ropa o la exhibición del cuerpo), sociológicas (como el nivel de estudios o la orientación sexual) y de su estructura de valores en base al modelo de Hall-Tonna (Hall, 1995 y 2006; Korres \& Elexpuru, 2017). Según este modelo, los valores humanos pueden clasificarse en cuatro fases, cada una dividida en dos etapas: Fase 1. Supervivencia (etapas: supervivencia y seguridad); Fase 2. Pertenencia (etapas: familia e institución); Fase 3. Autoiniciativa (etapas: vocación y nuevo orden); Fase 4. Interdependencia (etapas: sabiduría y orden mundial);

b. Un análisis cualitativo multimodal de los perfiles de YouTube e Instagram (Caldeira, 2016; Jones, 2009), que observa el nombre de usuario, iconos, textos, composición general del perfil, imágenes (avatar, banner y publicaciones), tipo de representación (directa o indirecta) y emoción predominante; y un análisis audiovisual de los contenidos de ambas redes (Casetti \& Di Chio, 1990; Fedele, 2021), que atiende entre otros a los códigos narrativos y audiovisuales (visuales, sonoros, gráficos y sintácticos);

c. Un análisis cualitativo temático (Braun \& Clarke, 2006) y un análisis textual del discurso (Lovelock, 2019) de los contenidos de ambas redes con una categorización a posteriori mediante ATLAS.ti.

11 La muestra de influencers se ha seleccionado entre aquellas jóvenes microcelebridades de YouTube e Instagram que los datos más recientes mencionados anteriormente permiten definir como altamente populares entre la juventud, en base a los siguientes criterios, buscando la mayor diversidad posible entre los perfiles, y respetando el equilibrio entre sexos:

- Influencers presentes tanto en YouTube (YT, en la Tabla 1) como en Instagram (IG);

- Edades comprendidas entre 18 y 30 años (durante el trabajo de campo, es decir 2018-2019);

- Orientación sexual variada;

- Notoriedad variada (pero con más de 200000 seguidores en el canal de YouTube);

- Variedad temática de su canal de YouTube (según las propias categorías de la plataforma: entretenimiento, comedia, blogs y personas, consejos y estilo, etc.).

Los perfiles masculinos y femeninos seleccionados se recogen en la Tabla 1, ordenados según números de seguidores en YouTube.

Tabla 1.- Influencers analizados (datos actualizados al 08/05/2019, excepto para «Seguidores IG», columna cuyos datos están actualizados al 31/03/2020).

\begin{tabular}{|l|l|l|l|l|l|}
\hline Nombre & Sexo & Edad & Temática canal & Seguidores YT & Seguidores IG \\
\hline ElRubiusOMG & Masculino & 29 & Comedia & 34685631 & $10,9 \mathrm{M}$ \\
\hline AuronPlay & Masculino & 30 & Comedia & 15738486 & $7 \mathrm{M}$ \\
\hline Wismichu & Masculino & 25 & Entretenimiento & 8482040 & $3,3 \mathrm{M}$ \\
\hline
\end{tabular}




\begin{tabular}{|l|l|l|l|l|l|}
\hline Dulceida & Femenino & 28 & Consejos y estilo & 2126059 & $1,6 \mathrm{M}$ \\
\hline Celopan & Masculino & 22 & Entretenimiento & 2079778 & $501 \mathrm{k}$ \\
\hline Melo Moreno & Femenino & 30 & Entretenimiento & 1708765 & $797 \mathrm{k}$ \\
\hline Paula Gonu & Femenino & 26 & Gente y blogs & 1570015 & $1,9 \mathrm{M}$ \\
\hline Jaime Altozano & Masculino & 25 & Entretenimiento & 1382655 & $224 \mathrm{k}$ \\
\hline Herrejón & Femenino & 28 & Entretenimiento & 350858 & $526 \mathrm{k}$ \\
\hline La gata de Schrodinger & Femenino & 25 & Ciencia y tecnología & 208810 & $44,2 \mathrm{k}$ \\
\hline
\end{tabular}

Fuente: elaboración propia.

Para cada perfil se han analizado un vídeo de YouTube y seis posts de Instagram. Los vídeos se han seleccionado en base a criterios temporales (publicados entre enero de 2018 y septiembre de 2019) y temáticos: vídeos del género entrevistas -entre los que se incluyen los tags- y/o vlogs según la clasificación establecida por Scolari y Fraticelli (2019), puesto que en ambas tipologías los influencers se exponen a nivel personal, ya sea respondiendo a las preguntas de la audiencia, o manifestando su opinión sobre un tema concreto (Tabla 2).

Tabla 2.- Vídeos de YouTube analizados (datos actualizados a 10/09/2019).

\begin{tabular}{|l|l|l|l|l|l|l|}
\hline Autor/a & Título & Fecha & Duración & Likes & Comentarios & Visualizaciones \\
\hline ElRubiusOMG & $\begin{array}{l}50 \text { cosas sobre mí } \\
2019 \text { by Rubius }\end{array}$ & $04 / 08 / 2019$ & $5: 44$ & $11 \mathrm{M}$ & 14000 & 7683255 \\
\hline AuronPlay & $\begin{array}{l}\text { Cómo ligar (en la } \\
\text { Prehistoria) }\end{array}$ & $16 / 01 / 2019$ & $10: 35$ & 653000 & 7900 & 8310240 \\
\hline Wismichu & $\begin{array}{l}\text { Respondiendo a } \\
\text { vuestras preguntas } \\
\text { por la calle }\end{array}$ & $16 / 01 / 2018$ & $13: 23$ & 375000 & 10000 & 3580037 \\
\hline Dulceida & $\begin{array}{l}\text { Tag del YouTube } \\
\text { hipócrita - dulceida }\end{array}$ & $28 / 02 / 2018$ & $7: 08$ & 42000 & 1827 & 759455 \\
\hline Celopan & $\begin{array}{l}\text { Preguntas que he } \\
\text { evadido - Celopan }\end{array}$ & $14 / 04 / 2019$ & $12: 12$ & 8400 & 464 & 94566 \\
\hline Melo Moreno & $\begin{array}{l}\text { ¿Me ha gustado } \\
\text { del YouTuber? Tag } \\
\text { honesto YouTuber }\end{array}$ & $13 / 03 / 2018$ & $14: 20$ & 42000 & 1508 & 2916 \\
\hline
\end{tabular}




\begin{tabular}{|c|c|c|c|c|c|c|}
\hline Paula Gonu & $\begin{array}{l}\text { Reaccionando a lo } \\
\text { que suponéis sobre } \\
\text { mí / @paulagonu }\end{array}$ & $29 / 03 / 2019$ & $11: 28$ & 25000 & 1398 & 453516 \\
\hline $\begin{array}{l}\text { Jaime } \\
\text { Altozano }\end{array}$ & $\begin{array}{l}\text { Todo sobre mí - } \\
\text { Especial } 1 \text { Millón } \\
\text { de Suscriptores / } \\
\text { Jaime Altozano }\end{array}$ & $04 / 03 / 2019$ & $36: 04$ & 103000 & 5307 & 1372892 \\
\hline Herrejón & $\begin{array}{lr}\text { Lo que suponéis } \\
\text { sobre mi } & \text { (¿soy } \\
\text { borde? } & \text { ¿soy } \\
\text { bisexual?), } & \text { etc. / } \\
\text { herrejón } & \end{array}$ & $14 / 04 / 2019$ & $12: 56$ & 12000 & 226 & 212361 \\
\hline $\begin{array}{l}\text { La gata de } \\
\text { Schrodinger }\end{array}$ & $\begin{array}{l}\text { ¿Cómo llevo ser } \\
\text { YouTuber? } \\
\text { ¿Trabajo para la } \\
\text { CIA? / preguntas y } \\
\text { respuestas }\end{array}$ & $17 / 07 / 2018$ & 13:07 & 13000 & 1243 & 144370 \\
\hline
\end{tabular}

Fuente: elaboración propia.

Los posts de Instagram se han seleccionado en base a criterios temporales, escogiendo las últimas seis publicaciones de cada influencer a fecha de 30 de septiembre de 2019.

\section{Resultados}

\section{Las representaciones de género de los «personajes» influencers}

15 La combinación del análisis socio-semiótico (Fedele, 2014; Korres \& Elexpuru, 2017) y de las estructuras de valores (Hall, 1995, 2006) ha permitido identificar las principales características físicas, sociales y psicológicas de los influencers, abordando el primer sub-objetivo del estudio.

Aunque este estudio ha buscado la diversidad expresa en los criterios de género y orientación sexual, los resultados del análisis muestran poca disparidad en dichos aspectos. Por ejemplo, por lo que se refiere al género, solo una persona se identifica a sí misma como de género no binario (Melo), mientras que, para encontrar a un hombre no heterosexual (Celopan), ha habido que descender bastante en los listados de influencers más populares en la fase de selección de la muestra. Por lo tanto, cuatro de los hombres analizados son heterosexuales, mientras solo uno es homosexual. Entre las influencers de sexo femenino, sin embargo, hay una mayor variedad de orientaciones sexuales, ya que Melo es homosexual y Dulceida y la Gata de Schödinger bisexuales, siendo las otras dos mujeres heterosexuales. Asimismo, también hay una mayor diversidad en otros aspectos que afectan, sobre todo, a su representación física (Figura 1), tanto en cuanto a la constitución física (por ejemplo Melo entra dentro de la categoría «fuerte»), como a la vestimenta (más «trendy» en aquellas que dedican su canal al lifestyle y más "casual» en el resto de casos) y la voluntad de provocar de forma sexual mediante la exhibición del cuerpo (Dulceida y Paula Gonu). 
Figura 1. - Las influencers Maria Herrejón, Paula Gonu y La Gata de Shrödinger (Rocío Vidal), Dulceida (Aida Domènech) y Melo Moreno.
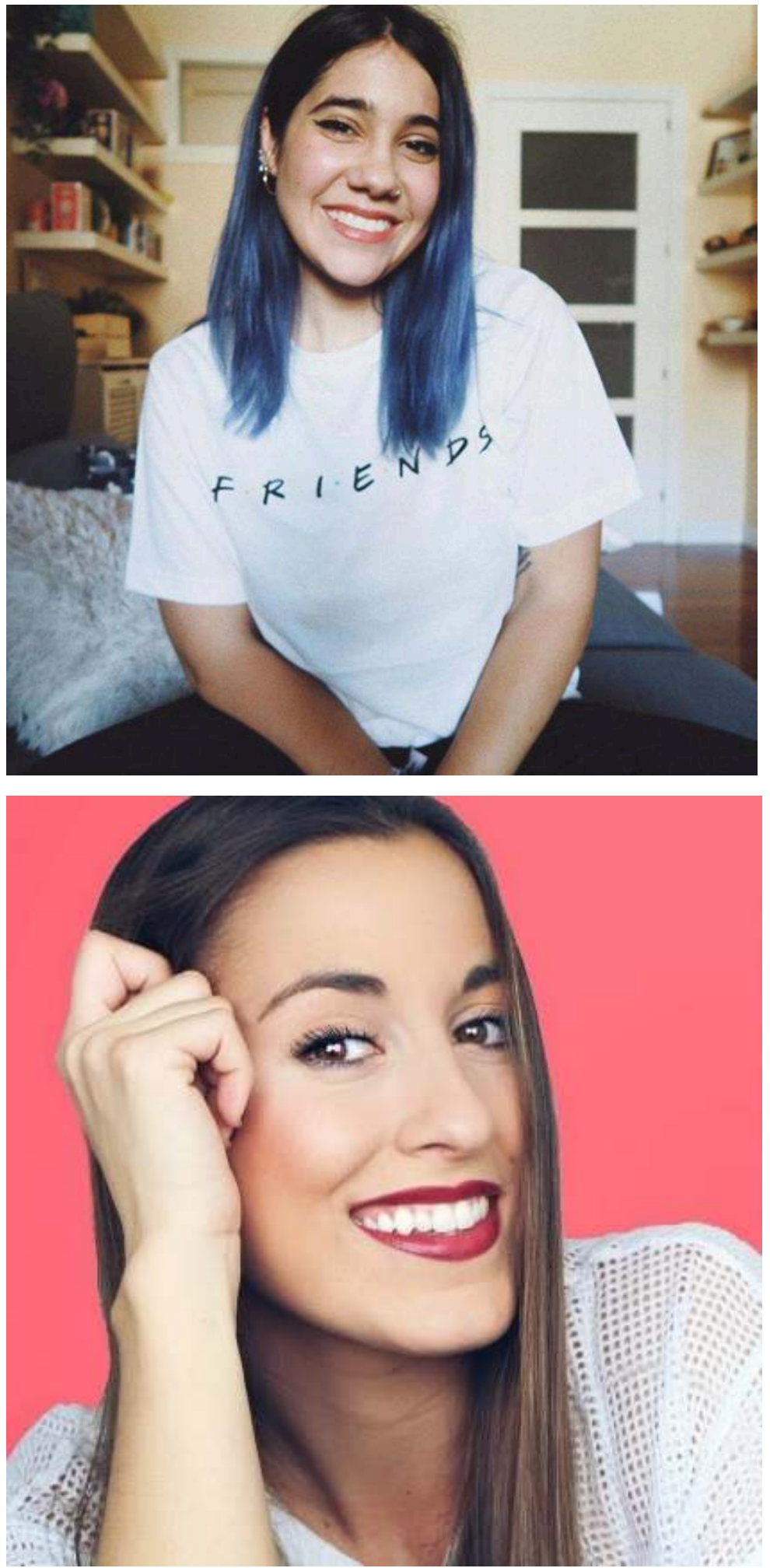

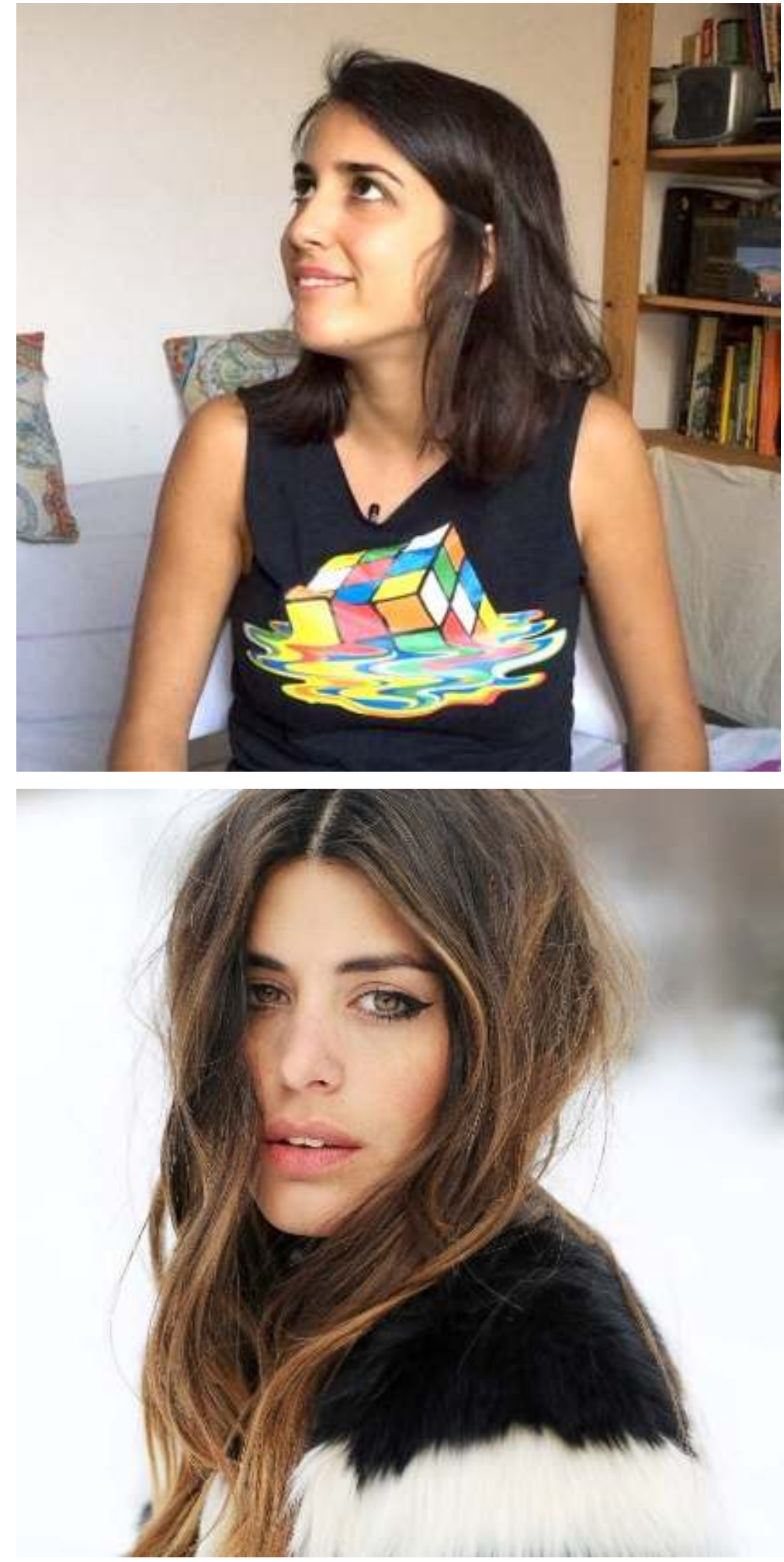


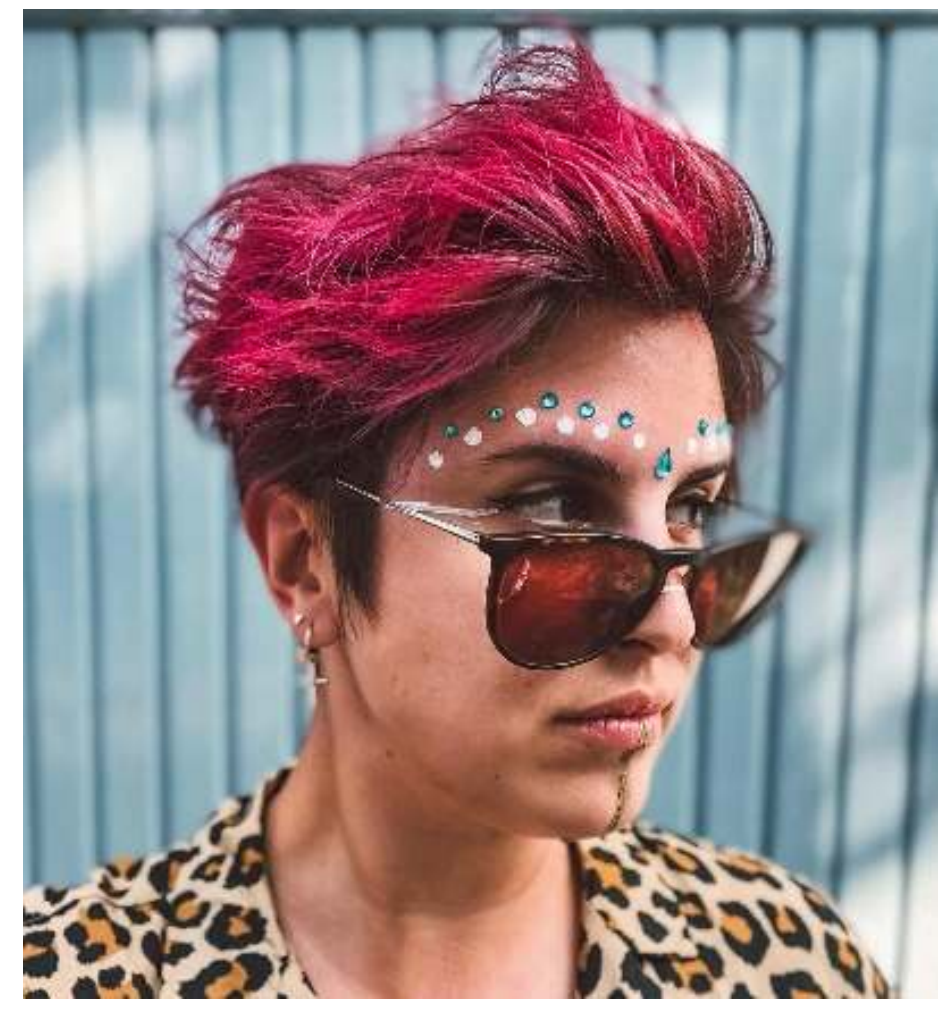

Fuente: <https://n9.cl/qjli2>, YouTube (captura), <https://n9.cl/po60py>, <https://n9.cl/vbq3> (30/09/2019).

Paula Gonu y Dulceida responden a una feminidad totalmente normativa de acuerdo con su manera de vestir y su tendencia a enseñar su cuerpo apelando a la mirada masculina, que además coincide con la adhesión a los indicadores visuales de la feminidad (Dobson, 2014) y a una exhibición casi total del yo, sobre la que se ejerce mayor control. Por ejemplo, mientras sus compañeras eligen (auto)representarse en el avatar y/o en el banner de su canal de YouTube mediante dibujos (Herrejón y La Gata de Schrödinger) o diseños sin figuras humanas (Melo), Paula Gonu y Dulceida escogen fotografías de sí mismas. También en el caso de Instagram suelen aparecer solas. Esto resulta coherente con la temática de sus canales (lifestyle), así como su uso habitual del maquillaje y cierta tendencia a la exhibición del cuerpo heterosexy (Dobson, 2011) desde una posición, no obstante, de sujeto en lugar de objeto sexual (Gill, 2008).

Por su lado, Herrejón también enseña su cuerpo ocasionalmente, pero lo hace con un objetivo reivindicativo. En una de las publicaciones de Instagram analizadas, muestra una imagen (la única metonímica de la muestra) de sus piernas no con la finalidad de despersonalizarse sino todo la contrario, como se puede apreciar en el texto que la acompaña: «Pues este es mi cuerpo y mi realidad. Los surcos en las piernas llevan acompañándome (y acomplejándome) muchos años ya y la verdad es que por primera vez y por fin han dejado de hacerlo y estoy muy feliz con eso y con ellos» (Herrejón, Post de Instagram, 28/09/2019).

19 Tampoco Melo encaja en la representación normativa de la feminidad, puesto que es de constitución más «fuerte», nunca se maquilla y que viste con prendas que esconden sus atributos sexuales. La Gata de Schrödinger, por su lado, es una mujer «delgada» que viste de manera «casual», por ejemplo con camisetas de grupos de música. 
20 En el caso de los hombres (Figura 2), se detecta una menor diversidad en cuanto a los atributos físicos: todos son de constitución entre «delgada» y «normal», visten de forma «casual» (y en ocasiones añadiendo piezas deportivas) y no exhiben su cuerpo con finalidades eróticas sino más bien de provocación desde la irreverencia (este es el caso de Wismichu y elRubius, que se consideran a sí mismos trolls). Como mínimo dos de ellos (Auronplay y elRubius), según se ha podido observar en las publicaciones analizadas de Instagram, se adscriben explícitamente a la comunidad otaku, lo cual lleva asociado ciertos códigos y aficiones.

Figura 2. - Los influencers AuronPlay (Raúl Álvarez Genes), elRubius (Rubén Doblas Gundersen), Wismichu (Ismael Prego Botana), Celopan (David Calvo) y Jaime Altozano.

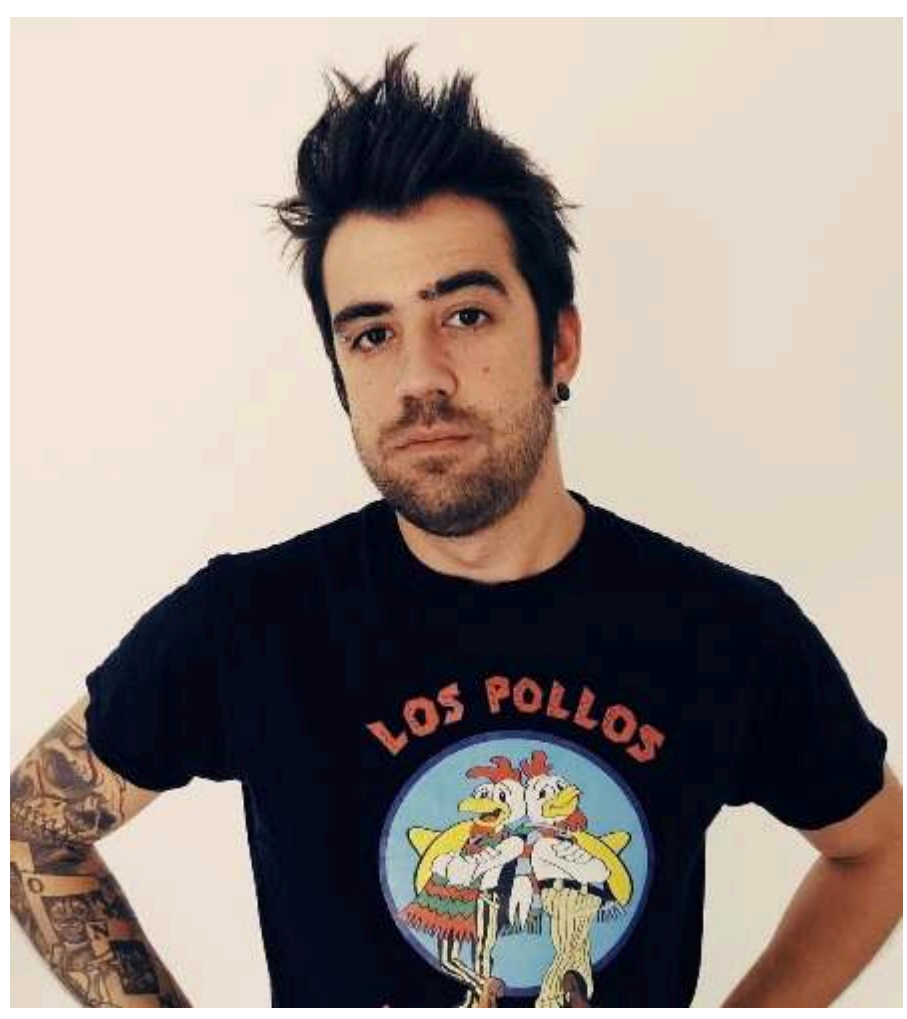



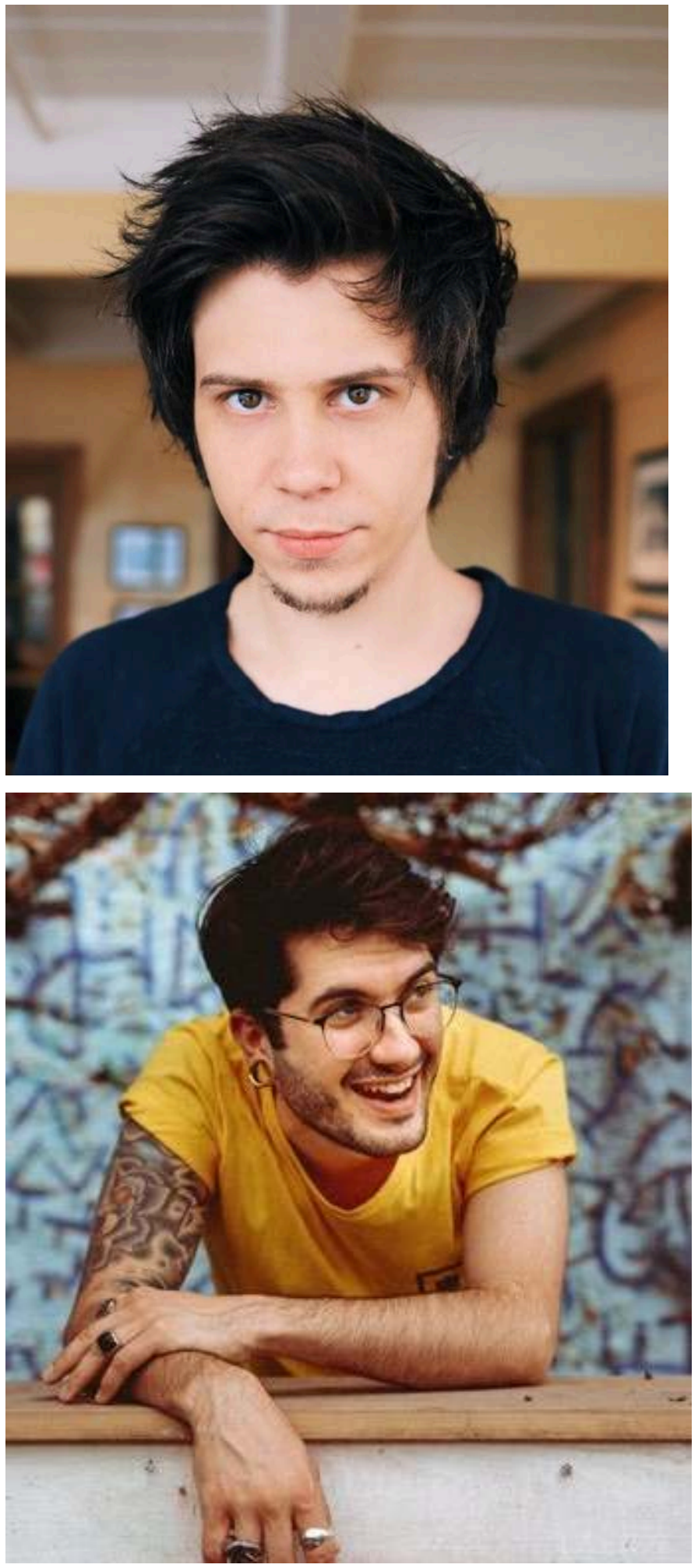

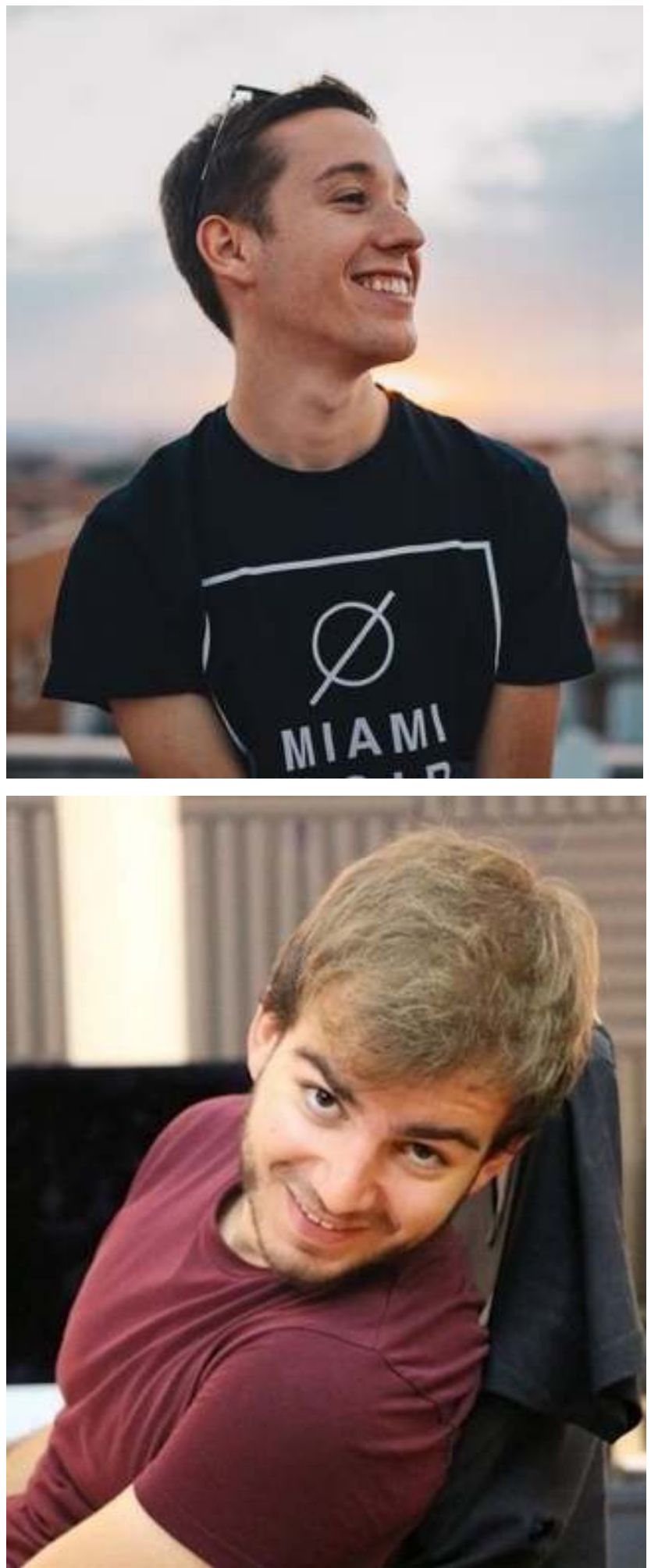

Fuente: <https://n9.cl/0tin5>, <https://n9.cl/s06vz>, Instagram (captura), YouTube (captura),<https:// n9.cl/l6sc $>(30 / 09 / 2019)$.

Desde el punto de vista de las características sociológicas, la mayoría de las microcelebridades de la muestra tienen estudios técnicos o superiores en ámbitos relacionados con la creatividad (audiovisual, en muchos casos). Se detecta un sesgo de género en la mayor formación de las mujeres (Herrejón y la Gata de Schödinger han 
cursado un máster), así como en las disciplinas (periodismo y/o publicidad en el caso de las mujeres, y comunicación audiovisual o diseño de videojuegos en el caso de los hombres).

Finalmente, por lo que se refiere a las características psicológicas de los influencers, estas se han analizado aplicando el modelo de estructura de valores de Hall-Tonna (Hall, 1995, 2006) a sus representaciones mediáticas, tal como se ha indicado en el apartado metodológico.

En los influencers de la muestra destaca una gran presencia de aquellos valores pertenecientes a la fase 3 de iniciativa personal, y en particular a las de vocación y nuevo orden. En general, predominan dos aspectos: por un lado, el valor máximo de autoafirmación ligado a la independencia, la limitación/aceptación y la calidad/ evaluación; por otro, la vertiente comunitaria y colaborativa de la propia tarea de influencer. No se han detectado diferencias en función del género dentro de las estructuras de valores.

\section{El lenguaje audiovisual y las representaciones de género}

Para abordar el segundo sub-objetivo se han llevado a cabo un análisis multimodal (Caldeira, 2016; Jones, 2009) y un análisis audiovisual (Casetti \& Di Chio, 1990; Fedele, 2021) de los perfiles y los contenidos mediáticos de los influencers de la muestra. Los resultados de estos análisis muestran que tanto los perfiles como los propios contenidos van destinados a construir una imagen de marca que, además, potencia los aspectos de la propia identidad, con un peso específico de la identidad de género.

El análisis de los códigos audiovisuales (códigos de iconicidad, visuales, gráficos, sonoros y sintácticos) no presenta marcadores de género, con la excepción del color y la luz, manipulados a través de la aplicación de filtros o mediante la iluminación de la escena, y de las paletas concretas de colores. Así pues, en tres de las cinco influencers de sexo femenino (Dulceida, Paula Gonu y Herrejón) y en el hombre homosexual (Celopan), la imagen de marca se vincula, de un modo $\mathrm{u}$ otro, a las tonalidades lila y/o rosa en sus perfiles (Figura 3). 
Figura 3. - Perfil de YouTube de Dulceida.

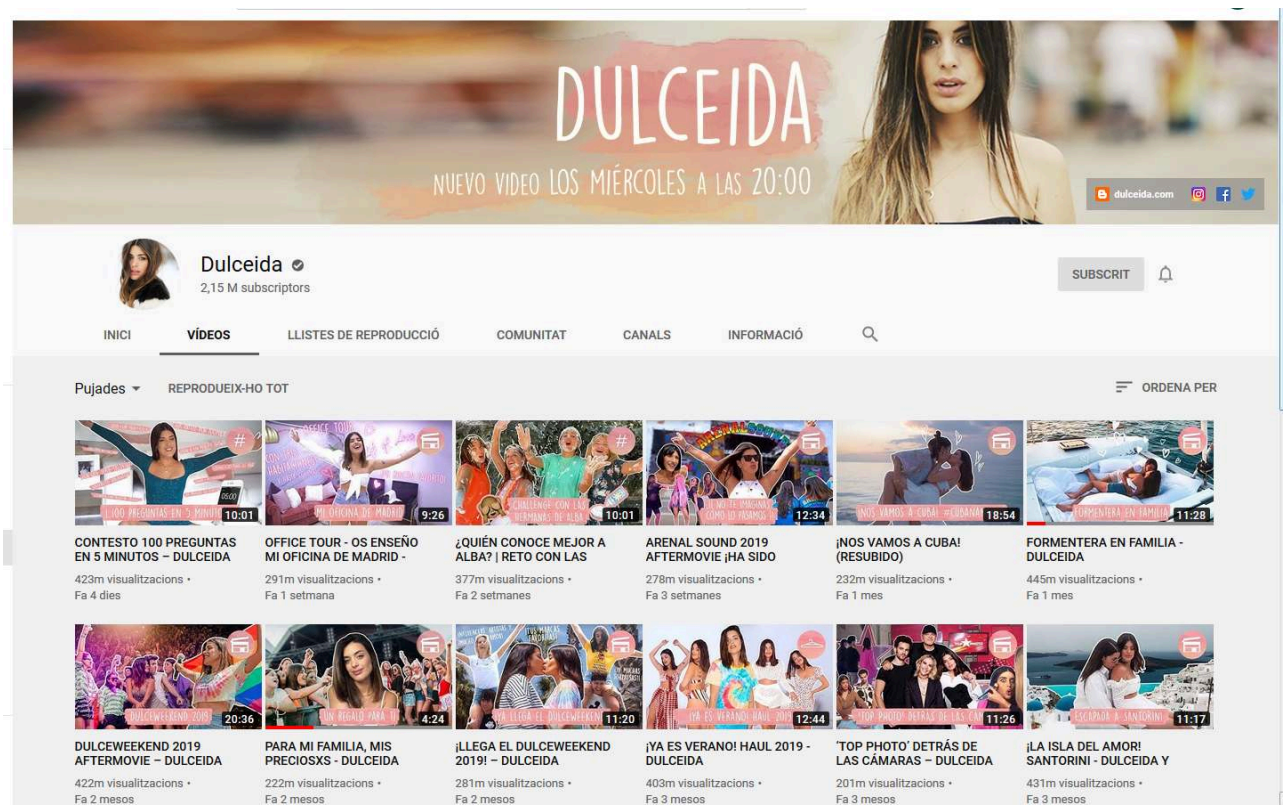

Fuente: YouTube (captura 30/09/2019).

El uso de colores vivos, sin embargo, es habitual en ambos sexos, y responde a los códigos propios del género audiovisual del que participan los influencers. De igual manera, el lenguaje digital traducido en el uso de emoticonos e hipertextos está muy presente. De todas maneras cabe destacar que, si bien el uso de emoticonos está extendido tanto entre influencers de sexo masculino como femenino, el corazón destaca en el repertorio de la mayoría de mujeres y de Celopan, según se observa en los textos relativos a las publicaciones de Instagram analizadas.

De todas maneras, los influencers hombres tienden más a representarse en su perfil a través de, o acompañados por, ilustraciones o carátulas que remiten a las actividades creativas que desarrollan dentro y fuera de las redes sociales, por ejemplo, elementos que atañen a los videojuegos en el caso de Auronplay o una serie de animación en el caso de el Rubius (Figura 4). 
Figura 4. - Perfil de YouTube de ElRubius.

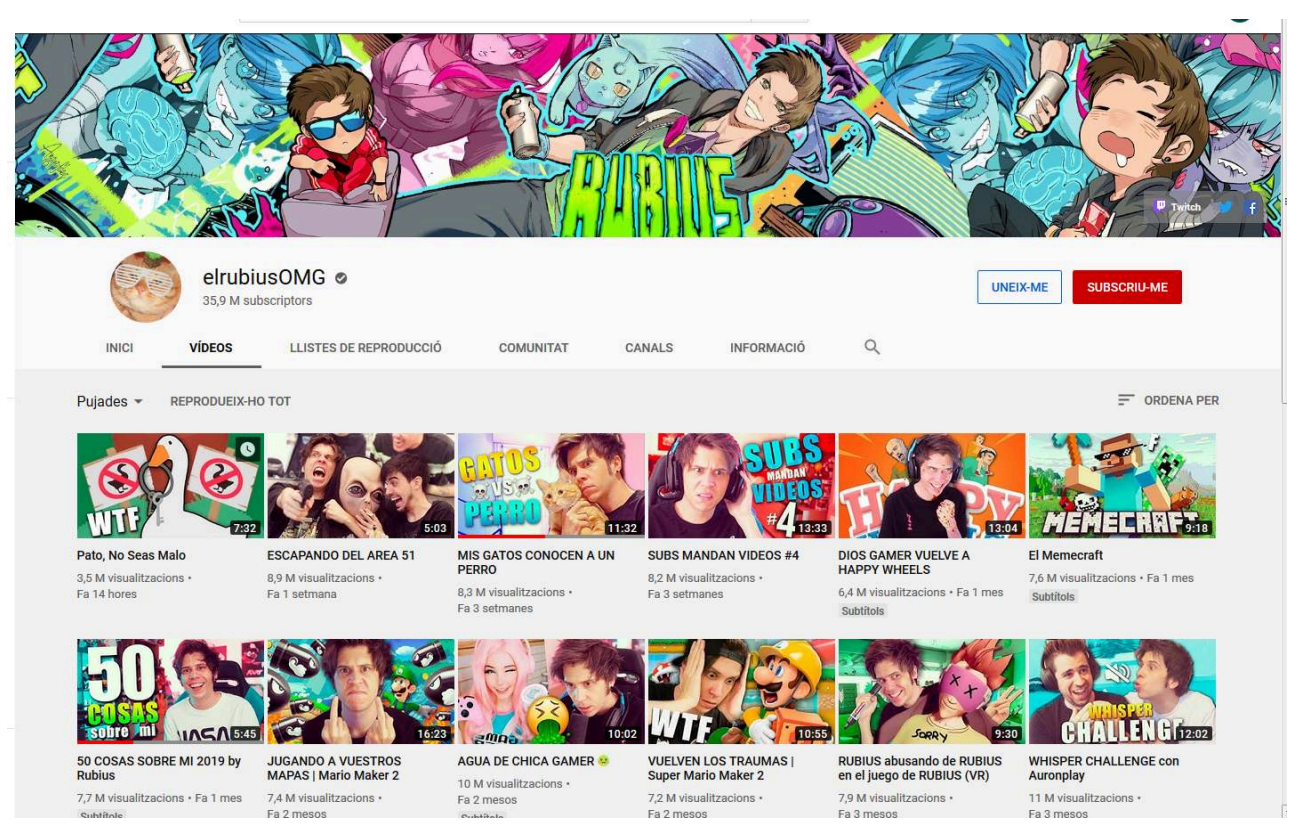

Fuente: YouTube (captura 30/09/2019).

Por lo que se refiere a los contenidos publicados en Instagram (fotografías y textos), si bien se detecta una tendencia generalizada en ambos sexos hacia la expresión de emociones positivas, habitualmente potenciadas mediante el uso de emoticonos, hay que destacar que las mujeres de la muestra se identifican con ella con mayor ahínco, respondiendo al estereotipo y a los preceptos tanto del postfeminismo como del feminismo popular. También la asiduidad de publicación durante el periodo analizado es mucho mayor en mujeres. Mientras los hombres no siempre aprovechan todas las potencialidades ofrecidas por Instagram, las mujeres despliegan una mayor variedad de fotografías propias y por tanto de autorepresentaciones directas por publicación, lo cual denota una mayor exposición de la imagen pública en dicha red social.

\section{Las representaciones de género en los contenidos de los influencers}

Para el tercer sub-objetivo se han realizado un análisis cualitativo temático (Braun \& Clarke, 2006) y un análisis textual del discurso (Lovelock, 2019) de los contenidos de los diez influencers de la muestra.

Por lo que se refiere a referencias explícitas a discursos entorno al género y/o el feminismo o el colectivo LGBTIQ*, entre las influencers mujeres se detecta una cierta familiaridad (consciente o inconsciente) con el body positive movement, si bien sólo dos de las cinco influencers de sexo femenino (Herrejón y La Gata de Schrödinger) se adhieren al feminismo de forma explícita en los contenidos analizados. Lo que todas tienen en común, pues, es la promoción de la (auto)confianza vinculada al cuerpo y una cierta defensa de la extensión del cánon de belleza (Fernández, 2017). No obstante, tal como apunta Gill (2016), existe una cierta traslación del ideal de belleza a la mente, siendo Paula Gonu y Dulceida sus principales promotoras. Las demás, no obstante, también adoptan actitudes positivas como parte de su tarea como influencers: Melo y La Gata de Schrödinger responden a los haters con sentido del humor y confianza. Según Banet-Weiser (2018) esta es la estrategia que el feminismo popular ha privilegiado 
frente a los ataques machistas. Puesto que la promoción de la autoconfianza y la actitud positiva es común al postfeminismo y al feminismo popular, se puede decir que las influencers de sexo femenino de la muestra se posicionan entre ambos.

31 Cabe resaltar que en por lo menos dos de los cinco casos hay, además, una adopción de una posición constructivista y flexible acerca de la propia identidad y la sexualidad, lo cual no deja de ser un rasgo generacional de la denominada «gender fluid generation» (Bragg, Renold, Ringrose \& Jackson et al., 2018; Marsh, 2016).

32 Entre los influencers hombres se han identificado rasgos de un tipo de masculinidad más hegemónica, sobre todo en aquellos más populares, si bien se combinan con otros aparentemente contradictorios. Por ejemplo, el vídeo analizado de AuronPlay es una deconstrucción de la masculinidad tóxica a través de la crítica a quien él denomina «el ligón de la prehistoria». En el vídeo, el influencer comenta y critica otro vídeo de YouTube en el que ese supuesto «ligón de la prehistoria» da «consejos» (heteronormativos y hasta machistas) a otros chicos sobre cómo ligar con mujeres. Sin embargo, la reacción que AuronPlay propone ante dicho individuo y sus actitudes sexistas es, en clave de humor, la violencia: «cómo le vas a decir eso a alguien por el amor de Dios, solo vas a ganar que te metan tres puñetazos en el hígado. Y merecidos» (AuronPlay, vídeo 16/01/2019). AuronPlay comparte con otros YouTubers (sobre todo con Wismichu) el uso de tacos y groserías, que además en su caso se convierten en un uso exacerbado de la escatología para generar humor, respondiendo de alguna manera al estereotipo masculino tradicional.

ElRubius, por su lado, se muestra incómodo ante la perspectiva de mostrar vulnerabilidad, lo cual según Badinter (1993) y Connell (2005) es una de las bases de la masculinidad hegemónica; cada vez que dice algo bonito lo hace con un tono jocoso y a menudo necesita puntualizar su veracidad. Es además el único de los YouTubers de la muestra que explícitamente sexualiza a las mujeres, tanto a través de las imágenes como del discurso, y en repetidas ocasiones, lo cual responde también a los códigos propios de la comunidad otaku.

34 Sin embargo, llama la atención el uso del lenguaje inclusivo en la totalidad de influencers analizados, así como la total aceptación de la homosexualidad, que es a su vez un rasgo generacional y la base de la masculinidad inclusiva (Anderson, 2011) o cuanto menos híbrida (Maloney et al., 2018).

El cariño que profesan todos los influencers analizados tanto hacia sus fans como hacia sus compañeros puede ser una muestra de las relaciones homosociales que establecen y que los acercan más a las masculinidades inclusivas. Wismichu y Jaime Altozano, a su vez, son interpelados por su público de manera directa acerca de los derechos LGTBIQ*, respecto a los que ambos se manifiestan «muy a favor». Wismichu habla explícitamente de machismo y se muestra arrepentido por sus actitudes pasadas. Por último, Celopan es abiertamente homosexual y se refiere habitualmente a sí mismo en femenino ("perra», «payasa», «divina») con humor en las publicaciones de Instagram analizadas.

36 Tanto él como Jaime Altozano, los dos influencers de sexo masculino de la muestra con menos seguidores, presentan un tipo de masculinidad más inclusiva, si bien Celopan se acerca en su idea de la familia a la homonormatividad (por ejemplo en su ilusión por casarse). En otro orden de cosas, tanto Jaime Altozano como Celopan manifiestan su deseo de ser padres, aunque ninguno muestra prisa. En los vídeos y publicaciones de 
Instagram analizados, ambos hablan extensamente de su relación de pareja (que los demás solo citan de soslayo) y de la importancia de dicho vínculo afectivo en su vida.

\section{Conclusiones}

del lenguaje audiovisual y de los recursos visuales propios de YouTube e Instagram. Todos los influencers analizados hacen un amplio uso de colores vivos y recursos audiovisuales variados, uso que está sobre todo al servicio de la construcción de sus identidades de marca. Solo en algunos códigos visuales (paletas de colores e iluminación) y gráficos (emoticonos) se detectan diferencias de género: tres de las cuatro mujeres usan como paleta de colores principal las tonalidades rosa y/o lila, y se ha detectado un uso más destacado de emoticones y emociones positivas en las influencers mujeres (respondiendo al estereotipo y a los preceptos tanto del postfeminismo como del feminismo popular) y en el único hombre homosexual de la muestra. (auto)representación de género presente en los contenidos mediáticos producidos por los influencers. En este sentido, los resultados apuntan a la presencia de ciertos elementos propios de la feminidad y la masculinidad tradicionales, aunque también a representaciones de género más inclusivas e igualitarias.

41 En el caso de los hombres, se han detectado rasgos de masculinidad más hegemónica en aquellos más populares que, respondiendo al estereotipo masculino tradicional, en algunos casos usan como recursos humorísticos la rebeldía, las groserías e incluso la violencia simbólica. Sin embargo, la mayoría de ellos también hace uso del lenguaje neutral, dirigiéndose tanto a chicos como a chicas, no presuponiendo la heterosexualidad de nadie y mostrando apoyo y respeto hacia el colectivo LGTBIQ*. De hecho, son generalmente críticos (y autocríticos) con las actitudes machistas, mientras 
que algunos reivindican identidades de género no normativas, así como nuevos modelos de masculinidad, mediante elementos de deconstrucción de la masculinidad «tóxica» y referencias a una masculinidad inclusiva o híbrida (Anderson, 2009; Maloney et al., 2018), sobre todo en relación a la homosexualidad, también como rasgo generacional. También hay que destacar la incomodidad de algunos hombres heterosexuales en cuanto a mostrarse vulnerables, lo que, según Badinter (1993) y Connell (2005), es una de las bases de la masculinidad hegemónica.

Por su parte, la mayoría de las influencers de sexo femenino adoptan posiciones feministas y críticas con los estereotipos de género, defendiendo por tanto el valor de la igualdad de género. En particular, puede notarse que convive una representación de la feminidad normativa - con rasgos de la «gender fluid generation» (Bragg et al., 2018; Marsh, 2016) - , con una posición más flexible y constructivista de la feminidad. También entre las mujeres se detecta una cierta familiaridad (consciente o inconsciente) con el body positive movement, si bien sólo dos (Herrejón y la Gata de Schrödinger) de las cinco influencers de sexo femenino se adhieren al feminismo de forma explícita.

Por lo tanto, la principal conclusión de este estudio es la variedad de modelos, estereotipos y representaciones mediáticas encontradas, una variedad que permite la difusión de representaciones más inclusivas, alejadas de los estereotipos de género hegemónicos, y ligadas a nuevos modelos de feminidad y masculinidad. Ello no significa que las microcelebridades no estén bajo la tensión de una ética neoliberal y sus exigencias, como recogen Ashman, Patterson y Brown (2018). Aún así, los influencers analizados muestran una gran sensibilidad hacia la igualdad y la diversidad de género, y la gran mayoría integra la perspectiva de género en sus discursos, de manera más o menos explícita. Por lo tanto, puede afirmarse que los influencers analizados proponen mayoritariamente nuevos modelos de feminidad y masculinidad no hegemónicas, incluida la posibilidad de género no binario, $\mathrm{y}$, por lo tanto, más igualitarios e inclusivos. Así, su rol en el proceso de socialización de adolescentes y jóvenes puede ser positivo, y puede contribuir a la construcción de un imaginario juvenil más inclusivo e igualitario, a pesar de las lógicas individualistas y económicas que subyacen a las figuras de las microcelebridades.

\section{BIBLIOGRAFÍA}

ABIDIN Crystal \& COVER Robert I. (2018), «Gay, famous and working hard in YouTube: influencers, queer microcelebrity publics and discursive activism», P. Aggleton, R. Cover, D. Leahy, D. Marshall \& M. L. Rasmussen (eds), Youth, sexuality and sexual citizenship, London: Routledge, 217-231.

AIMC Asociación para la investigación de medios de comunicación (2020), Estudio General de Medios (EGM). Marco General de los medios en España 2020, <https://www.aimc.es/a1mc-cont3nt/ uploads/2020/01/marco2020.pdf>. 
ANDERSON Eric (2009), Inclusive masculinity: the changing nature of masculinities, New York: Routledge.

ANDERSON Eric (2011), «Masculinities and sexualities in sport and physical cultures: Three decades of evolving research», Journal of Homosexuality, 58(5), 565-578, <https://doi.org/ 10.1080/00918369.2011.563652>.

ANDERSON Monica \& JIANG Jingjing (2018), Teens, social media and technology 2018, Pew Research Center, <https://www.pewresearch.org/internet/wp-content/uploads/sites/9/2018/05/ PI_2018.05.31_TeensTech_FINAL.pdf>.

ARAN-RAmSPotT Sue, Fedele Maddalena \& TARRAGó Anna (2018), «YouTubers' social functions and their influence on pre-adolescence», Comunicar, XXVI(57), <https://doi.org/gc8p>.

ARNETT Jeffrey J. (1995), «Adolescents' uses of media for self-socialization», Journal of Youth and Adolescence, 24, 519-533, <https://doi.org/10.1007/BF01537054>.

Ashman Rachel, PATTERSON Anthony \& BRown Stephen (2018), «Don't forget to like, share and subscribe': Digital autopreneurs in a neoliberal world», Journal of Business Research, 92, 474-483, <https://doi.org/10.1016/j.jbusres.2018.07.055>.

BADINTER Elisabeth (1993), La identidad masculina, Alianza Editorial.

BANET-WeISER Sarah (2011), «Branding the Post-Feminist Self: Girls’ Video Production and YouTube», C. Kearney (ed.), Mediated Girlhoods: New Explorations of Girls' Media Culture, New York: Peter Lang.

BANET-WeISER Sarah (2018), Empowered: Popular Feminism and Popular Misogyny, Durham: Duke University Press.

BAUMAN Zygmunt (2001), Modernidad líquida, México DF: Fondo de Cultura Económica.

BECK Ullright (1992), Risk Society: Towards a New Modernity, London: SAGE.

BLANCo-RUIZ María Ángeles \& SÁINZ DE BARANDA Clara (2018), «Channels produced by LGBT+ YouTubers: gender discourse analysis», Observatorio (OBS*) Special Issue, 97-121, <https://doi.org/ 10.15847 /obsOBS0001386>.

BONAGA Héctor \& TURIEL Cristina (2016), Mamá, quiero ser YouTuber, Barcelona: Planeta.

BOYD danah (2014), It's Complicated: The Social Lives of Networked Teens, New Haven: Yale University Press.

BRAGg Sara, RENOLD Emma, RINGROSE Jessica \& JACKSON Carolyn P. (2018), «'More than boy, girl, male, female': exploring young people's views on gender diversity within and beyond school contexts», Sex Education 18(4), <https://doi.org/10.1080/14681811.2018.1439373>.

BRAUN Virgina y CLARKE Victoria (2006), «Using thematic analysis in psychology», Qualitative Research in Psychology, 3(2), 77-101, <https://doi.org/10.1191/1478088706qp063oa>.

CABAllero Antonio, ToRTAJADA Iolanda \& Willem Cilia (2017), «Autenticidad, marca personal y agencia sexual: el posfeminismo lésbico en YouTube», Investig. Fem (Rev.), 8(2), 353-368, <https:// doi.org/10.5209/INFE.55005>.

CALdeira Sofia P. (2016), «Identities in Flux: An Analysis to Photographic Self-Representation on Instagram», Observatorio (OBS*) Journal, 10(3), 135-158, <https://doi.org/10.15847/ obsOBS10320161031>. 
CAMPOS DE CERQUeIDA Lígia (2017), «Postfeminist Heroines: Contradictions of Female Audiovisual Production on YouTube», Estudos Feministas, 25(3), 530, <https://doi.org/

10.1590/1806-9584.2017v25n3p1359>.

CASETTI Francesco \& Di CHIO Federico (1990), Analisi del film, Milano: Bompiani.

COCHRANE Kira (2013), All the rebel women: the rise of the fourth wave of feminism, London: Guardian Books.

ConNell Raewyn W. (2005), Masculinities, Los Angeles, CA: University of California Press.

COVER Rob (2012), «Performing and undoing identity online: Social networking, identity theories and the incompatibility of online profiles and friendship regimes», Convergence: The International Journal of Research into New Media Technologies, 18(2), 177-193, <https://doi.org/ $10.1177 / 1354856511433684>$.

Deuze Mark (2011), «Media Life», Media, Culture \& Society, 33(1), 167-148, <https://doi.org/ $10.1177 / 0163443710386518>$.

DeuZE Mark (2012), Media Life, Cambridge: Polity Press.

DoBson Amy S. (2011), «Hetero-sexy representation by young women on MySpace: The politics of performing an 'objectified' self», Outskirts: Feminisms along the edge, 25, 1-14, <https:// espace.library.uq.edu.au/view/UQ:353756>.

DoBson Amy S. (2012), «"Individuality is everything”: “Autonomous” femininity in MySpace mottos and self descriptions», Continuum: Journal of Media \& Cultural Studies, 26(3), 371-383, <https://doi.org/10.1080/10304312.2012.665835>.

DoBson Amy S. (2014), “"Sexy” And "Laddish” Girls: Unpacking complicity between two cultural imag(inations)es of young femininity», Feminist Media Studies, 14(2), 253-269, <https://doi.org/ 10.1080/14680777.2012.713866>.

EUROSTAT (2018), Being Young in Europe today, <https://ec.europa.eu/eurostat/statistics-explained/ index.php/Being_young_in_Europe_today>.

FEDELE Maddalena (2011), El consum adolescent de la ficció seriada televisiva (tesis doctoral), Bellaterra, Universitat Autònoma de Barcelona, <https://www.tdx.cat/handle/ 10803/83502\#page $=1>$.

FEDELE Maddalena (2014), Young characters in television fiction: youth identities, models and portrayals in the digital age, Barcelona: Universitat Pompeu Fabra, Departament de Comunicació, <https:// doi.org/gh5v>.

FEDELE Maddalena (2021), «La segunda generación de teen series: programas estadounidenses, británicos y españoles de los 2000-2010», Index.Comunicación, 11(1), 297-327, <https:// journals.sfu.ca/indexcomunicacion/index.php/indexcomunicacion/article/view/765>.

FedelE Maddalena, ARAN-RAMSPOTT Sue \& SuAu Jaume (2021), «YouTube Preferences and Practices of Preadolescents: Findings From a Study Carried Out in Catalonia», Comuncaçao e Sociedade, 39, 145-166, <https://doi.org/10.17231/comsoc.39(2021).2714>.

Ferchaud Arienne, GrZeslo Jenna, ORME Stephanie \& LAGroue Jared (2018), «Parasocial attributes and YouTube personalities: Exploring content trends across the most subscribed YouTube channels», Computers in Human Behaviour, 80, 88-96, <https://doi.org/10.1016/j.chb.2017.10.041>. FERNÁNDEZ Lola (2017), «El feminismo como producto mediático: la paradoja Beyoncé», Revista de Investigaciones Feministas, 8(2), 457-474, <https://doi.org/10.5209/INFE.54975>. 
FERNÁNDEZ-CRUZ Francisco \& FERNÁNDEZ-DíAZ María-José (2016), «Generation Z's teachers and their digital skills», Comunicar, 46, 97-105, <https://doi.org/10.3916/C46-2016-10>.

GARCíA JimÉnez Antonio, GARCía Beatriz \& LóPEz DE AyAla María Cruz (2016), «Adolescents and YouTube: creation, participation and consumption», Prisma Social, 1, 60-89, <https:// revistaprismasocial.es/article/view/1314>.

GARMENDIA Maialen, JiMÉNEZ Estefanía, KARRERA Iñaki, LARRAÑAGA Nekane, CASADO Miguel Ángel, MARTíneZ Gemma \& GaRITAONANDIA Carmelo (2019), Actividades, Mediación, Oportunidades y Riesgos online de los menores en la era de la convergencia mediática, León, España: Instituto Nacional de Ciberseguridad (INCIBE).

GIDDENS Anthony (1995), Modernidad e identidad del yo: el yo y la sociedad en la época contemporánea, Barcelona: Península.

GILL Rosalind (2007), «Postfeminist Media Culture: Elements of a Sensibility», European Journal of Cultural Studies, 10(2), 147-166, <https://doi.org/10.1177/1367549407075898>.

HALl Brian P. (1995), Values shift: A guide to personal and organizational transformation, Twin Lights Publications.

HALl Brian P. (2006), Values shift: A guide to personal and organizational transformation, Wipf and Stock Publishers.

IAB SPAIN (2018), Estudio anual de redes sociales, <https://iabspain.es/estudio/estudio-anual-deredes-sociales-2018/> (9 de abril de 2018).

ITO Mizuko, BAUMER Sonja, BITTANTI Matteo, BOYD danah, CoDy Rachel [...] TRIPP Lisa (2010), Hanging Out, Messing Around, and Geeking Out: Kids Living and Learning with New Media, Cambridge, Massachusetts: The MIT Press.

JenkINS Henry, ITO Mizuko \& BOYD danah (2016), Participatory Culture in a Networked Era. A Conversation on Youth, Learning, Commerce, and Politics, Cambridge: Polity.

JONES Rodney H. (2009), «Technology and sites of display», C. Jewitt (ed.), The Routledge Handbook of Multimodal Analysis, 114-126, London: Routledge.

KelleR Jessalyn \& RyAN Maureen E. (2018), Emergent Feminisms: Complicating a Postfeminist Media Culture, New York: Routledge.

KORRES Oihane \& ELEXPURU Iciar (2017), «Analysis of the values perceived by adolescents through television viewing. Values perceived by adolescents through TV viewing», Journal for the Study of Education and Development, 40(4), 782-811, <https://doi.org/10.1080/02103702.2017.1370821>.

LinARES-BAHILlo Estibaliz, ARISTEgUi-Fradua Iratxe \& BELoKi-MARAÑon Usue (2019), «YouTube, una plataforma para la (in)formación, relación, comunicación, diversión, y gestión de identidades (de género) en la natividad digital», Revista Mediterránea de Comunicación, 10(1), 55-70, <https:// doi.org/10.14198/MEDCOM2019.10.1.18>.

LOVELOCK Michael (2017), «'Is every YouTuber going to make a coming out video eventually?': YouTube celebrity video bloggers and lesbian and gay identity», Celebrity Studies, 8(1), 87-103, <https://doi.org/10.1080/19392397.2016.1214608>.

MALONEY Marcus, RoBerTS Steven \& CARUSo Alexandra (2018), «"Mmm... I love it bro!”: Performances of masculinity in YouTube gaming», New media \& Society, 20(5), 1697-1714, <https:// doi.org/10.1177/1461444817703368>. 
MANOvich Lev (2009), «The Practice of Everyday (Media) Life: from Mass Consumption to Mass Cultural Production», Critical Inquiry, 35(2), <https://doi.org/10.1086/596645>.

MARSH Sarah (2016), «The gender-fluid generation: young people on being male, female or nonbinary", The Guardian, <https://www.theguardian.com/commentisfree/2016/mar/23/genderfluid-generation-young-people-male-female-trans> (13 de septiembre de 2018).

MARWICK Alice (2015), «You may know me from YouTube. (Micro)-Celebrity in Social Media», P. D. Marshall \& S. Redmond (eds), A Companion to Celebrity, Hoboken, NJ: John Wiley \& Sons Inc.

MollynEAUX Heather, GiBSON Kerry, O’DONNELL Susan \& SINGER Janice (2008), «Exploring the Gender Divide on YouTube: An Analysis of the Creation and Reception of Vlogs», American Communication Journal, 10(2), <https://it.uu.se/edu/course/homepage/avint/vt09/1.pdf>.

MORRIS Max \& ANDERSON Eric (2015), «'Charlie Is So Cool Like’: Authenticity, Popularity and Inclusive Masculinity on YouTube», Sociology, 1-18, <https://doi.org/10.1177/0038038514562852>. MunRo Ealasaid (2013), «Feminism: a fourth wave?», Political Insight, 4(2), 22-25, <https://doi.org/ 10.1111/2041-9066.12021>.

NEWBERRY Christina (2021), «25 YouTube Statistics that May Surprise You: 2021 Edition», Hootsuite, <https://blog.hootsuite.com/youtube-stats-marketers/>.

OFсом (2019), Children and parents: Media use and attitudes report 2018, <https://www.ofcom.org.uk/ __data/assets/pdf_file/0024/134907/children-and-parents-media-use-and-attitudes-2018.pdf>. ORTEGA Iñaki \& VILANOVA Núria (2017), Generación Z: todo lo que necesitas saber sobre los jóvenes que han dejado viejos a los Millennials, Barcelona: Plataforma Editorial.

PÉREZ TORRES Vanessa, PASTOR Yolanda \& ABARROU Sara (2018), «Los YouTubers y la construcción de la identidad adolescente», Comunicar, XXVI(55), 61-70, <https://doi.org/10.3916/C55-2018-06>.

PRADEs Mariona \& CARBonell Xavier (2016), «Motivaciones sociales y psicológicas para usar Instagram», CP Communication Papers, 5(9), 27-36.

Press Andrea L. \& Williams Bruce A. (2010), The New Media Environment: An Introduction, WileyBlackwell, ISBN: 978-1-405-12768-4.

RASMUSSEN Leslie (2018), «Parasocial Interaction in the Digital Age: An Examination of Relationship Building and the Effectiveness of YouTube Celebrities», The Journal of Social Media in Society, Spring 2018, 7(1), 280-294.

RIHL Alexander \& WEGENERPP Claudia (2017), «YouTube celebrities and parasocial interaction: Using feedback channels in mediatized relationships», Convergence: The International Journal of Research into New Media Technologies, 1-13, <https://doi.org/10.1177/1354856517736976>.

SCOLARI Carlos \& FRATICELLI Damián (2016), «Nuevos sujetos mediáticos en el ecosistema de medios», V Congreso AsAECA, Buenos Aires.

SENFT Theresa M. (2008), Camgirls: Celebrity and community in the age of social networks, New York: Peter Lang.

STATISTA (2021), «Distribution of Instagram users worldwide as of January 2021, by age and gender», Statista, <https://www.statista.com/statistics/248769/age-distribution-of-worldwideinstagram-users/>.

TANKIVSKA Helene (2021), «YouTube - Statistics \& Facts», Statista, <https://www.statista.com/ topics/2019/youtube/\#dossierSummary__chapter2>. 
TER Bogt Tom F., Engels Rutger C., Bogers Sanne \& Kloosterman Monique (2010), «"Shake It Baby, Shake It": Media Preferences, Sexual Attitudes and Gender Stereotypes Among Adolescents», Sex Roles, 63(11-12), 844-859, <https://doi.org/10.1007/s11199-010-9815-1>.

Thumim Nancy \& ENLI Sara G. (2012), «Socializing and Self-Representation online: Exploring Facebook», Observatorio (OBS*) Journal, 6(1), 87-105.

VAISMAN Carmel L. (2016), «Pretty in pink, pretty in black: blogs as gendered avatars», Visual Communication, 15(3), 293-315, <https://doi.org/10.1177/1470357216643909>.

VAN-DIJCK José (2007), «Television 2.0: YouTube and the emergence of Homecasting», Creativity, Ownership and Collaboration in the Digital Age, 27-29, Cambridge: Massachusetts Institute of Technology.

WESTENBERG Wilma (2016), The influence of YouTubers in teenagers: a descriptive research of the role YouTubers play in the life of their teenage viewers (MA Thesis), University of Twente, Enschede.

Wotanis Lindsey \& McmiLlan Laurie (2014), «Performing Gender on YouTube. How Jenna Marbles negotiates a hostile online environment», Feminist Media Studies, 14(6), 912-928, <https://doi.org/ $10.1080 / 14680777.2014 .882373>$.

\section{RESÚMENES}

La investigación académica en comunicación ha destacado a menudo el papel de los medios en el proceso de socialización de adolescentes y jóvenes, en la construcción de sus identidades individuales y colectivas, y en la adquisición de valores, modelos y estereotipos, incluidos aquellos relacionados con las identidades de género. Precisamente social media como Instagram, Facebook, YouTube y TikTok son espacios privilegiados para la construcción y la (auto)representación de la identidad juvenil y de género, sobre todo a través de sus protagonistas, los llamados influencers o micro-celebrities.

Por tanto, el objetivo principal del presente artículo es identificar y analizar las representaciones mediáticas ofrecidas por jóvenes influencers españoles en relación a la construcción de las identidades de género (incluidos los géneros no binarios).

El diseño metodológico del estudio ha incluido un análisis socio-semiótico de diez influencers y de sus estructuras de valores, según el modelo de Hall-Tonna; un análisis cualitativo multimodal de los perfiles de YouTube e Instagram y un análisis audiovisual de los contenidos de ambas redes; un análisis cualitativo temático y un análisis textual del discurso de los contenidos seleccionados. Los resultados muestran que, aunque siga habiendo ciertos elementos normativos en cuanto a la representación de género, hay una buena variedad de modelos, estereotipos y representaciones mediáticas, que permite la difusión de representaciones no sexistas, alejadas de los estereotipos de género hegemónicos, y ligadas a nuevos modelos de feminidad y masculinidad más inclusivos.

Les recherches universitaires en communication ont souvent mis en évidence le rôle des médias dans le processus de socialisation des adolescents et des jeunes, dans la construction de leurs identités individuelles et collectives, et dans l'acquisition de valeurs, de modèles et de stéréotypes, y compris ceux liés aux identités de genre. Justement, les médias sociaux comme Instagram, Facebook, YouTube et TikTok sont des espaces privilégiés pour la construction et (l'auto) représentation de la jeunesse et de l'identité de genre, notamment à travers ses protagonistes, les soi-disant influenceurs ou micro-célébrités.

Par conséquent, l'objectif principal de cet article est d'identifier et d'analyser les représentations médiatiques proposées par les jeunes influenceurs espagnols en relation avec la construction des identités de genre (y compris les genres non binaires). 
La conception méthodologique de l'étude a inclus une analyse socio-sémiotique de dix influenceurs et de leurs structures de valeur, selon le modèle Hall-Tonna; une analyse multimodale qualitative des profils YouTube et Instagram et une analyse audiovisuelle des contenus des deux réseaux; une analyse thématique qualitative et une analyse textuelle du discours des contenus sélectionnés.

Les résultats montrent que, s'il y a encore certains éléments normatifs concernant la représentation $\mathrm{du}$ genre, il existe une bonne variété de modèles, de stéréotypes et de représentations médiatiques, ce qui permet la diffusion de représentations non sexistes, loin des stéréotypes de genre hégémoniques, et liées à de nouvelles modèles de féminité et de masculinité plus inclusive.

Academic research in media studies has often highlighted the role of the media in the socialization process of adolescents and young people, in the construction of their individual and collective identities, and in the acquisition of values, models and stereotypes, including those related to gender identities. Precisely social media such as Instagram, Facebook, YouTube and TikTok are privileged spaces for the construction and (self)representation of youth and gender identity, especially through its protagonists, the so-called influencers or micro-celebrities.

Therefore, the main objective of this article is to identify and analyze the media representations portrayed by young Spanish influencers in relation to the construction of gender identities (including non-binary genders).

The methodological design of the study has included a socio-semiotic analysis of ten influencers and their value structures, according to the Hall-Tonna model; a qualitative multimodal analysis of YouTube and Instagram profiles and an audiovisual analysis of the contents of both networks; a qualitative thematic analysis and a textual analysis of the discourse of the selected contents. The results show that, although there are still certain normative elements regarding gender representation, there is a good variety of models, stereotypes and media representations, which allows the dissemination of nonsexist representations, away from hegemonic gender stereotypes, and linked to new more inclusive models of femininity and masculinity.

\section{ÍNDICE}

Mots-clés: féminité, masculinité, LGTBIQ*, influenceurs, identité de genre, réseaux sociaux, Instagram, YouTube

Keywords: femininity, masculinity, LGTBIQ*, influencers, gender identity, social networks, Instagram, YouTube

Palabras claves: feminidad, masculinidad, LGTBIQ*, influencers, identidad de género, redes sociales, Instagram, YouTube

\section{AUTORES}

\section{MADDALENA FEDELE}

Centre de Recerca en Informació, Comunicació i Cultura, Facultat d'Informació i Mitjans

Audiovisuals, Universitat de Barcelona

maddalena.fedele@ub.edu

\section{ESTER VILLACAMPA}

DIGILAB, Facultat de Comunicació i Relacions Internacionals Blanquerna, Universitat Ramon Llull estervm1@blanquerna.url.edu 


\section{SUE ARAN-RAMSPOTT}

DIGILAB, Facultat de Comunicació i Relacions Internacionals Blanquerna, Universitat Ramon Llull suear@blanquerna.url.edu 